\title{
أثر الارتدادات الجانبية والخلفية في كمية الطاقة المسلطة على المبنى في النسيج الحضري في المشاريع السكنية
}

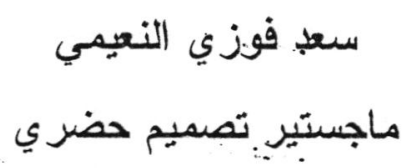

سعب فوزي النعيمي

ماجستبر تصميم حضري

\author{
د. دمثلد حيدر الجوادي \\ قسم الهندسة المعمارية \\ الجامعة التكنولوجية
}

الخلاصة

يعتبر التقارب بين البيوت في العمارة التر اثية من احدى المسببات الرئيسية في جعل الأحياء السكنية ذات منــاخ

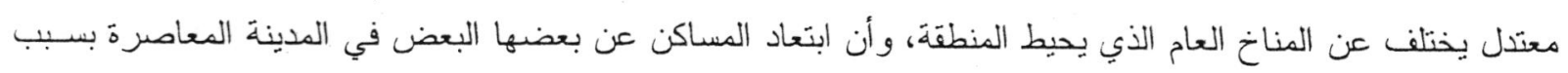

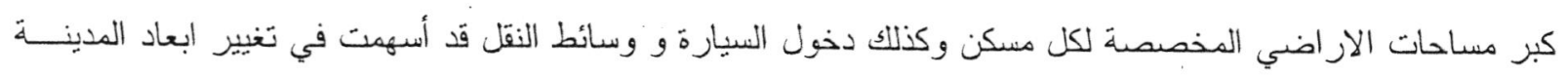

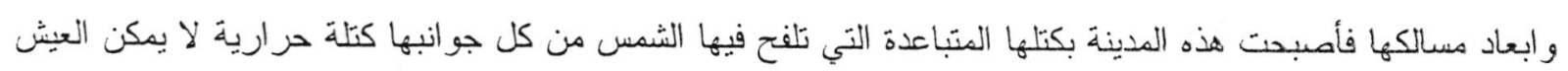
فيها الا بأجهزة تكييف اصطناعية كثيرة وكبيزة.

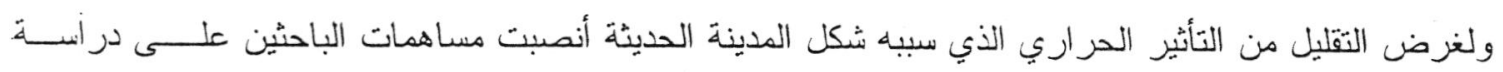

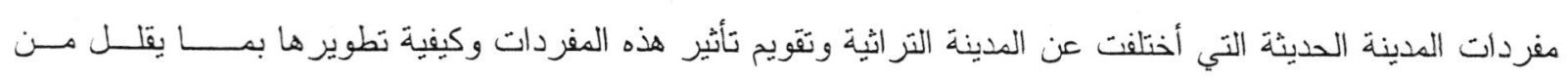

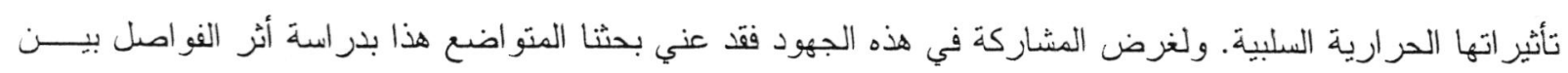

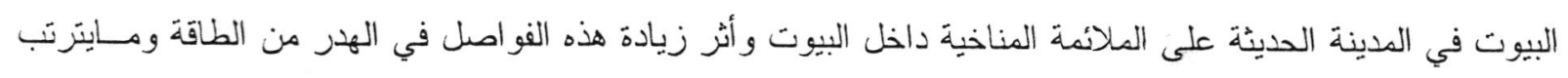

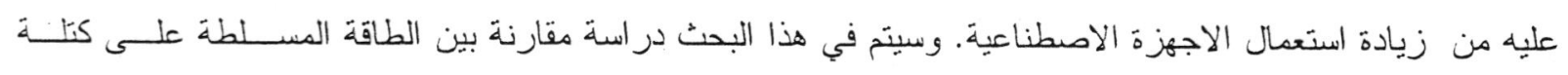

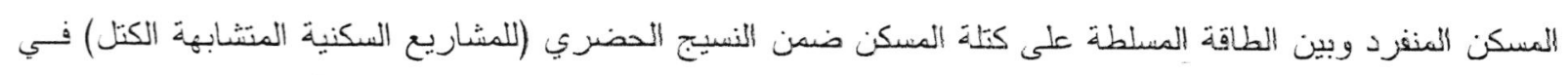

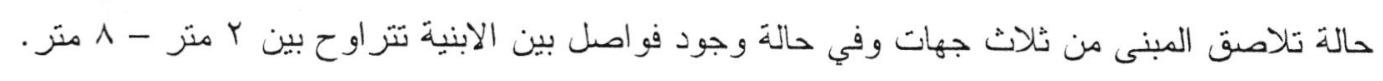

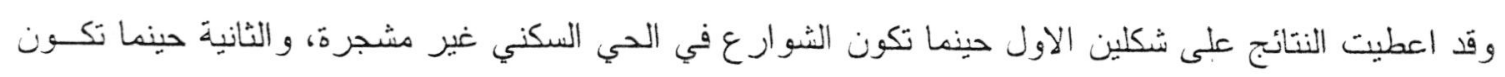

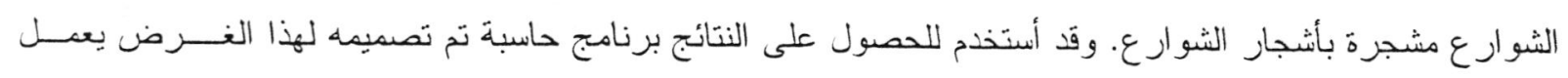

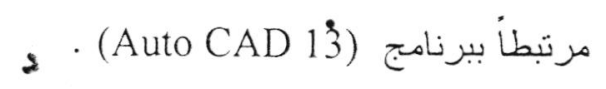


الفضاء غير قابل للأستخدام من التقلبـــــات الحراريـــة

\section{المقدمة}

داخله.

بموجب ما حدث في هذه البيوت مـــن تقلبــات

حرارية بدأت المنادات بالرجو ع الى أساليب المعالجات في البيوت التز اثية ولكننا كأشخاص عاشو ا في البيـوت التقليدية و عاشو ا في البيوت الحديثة لنا نظرتنا الخاصسة فنحن نبحث عن المحاسن في البيوت التقليدية و نحاول أخذها و تطويرها ضبن محــــــدات المدينـــة الحديثـــة ونستغنيد من السلبيات و نحـــاول الابثتعـاد عنـــها فــي تصناميمنا الحديثة.

ان من المزايا المناخية التي كانت فـــي بيوتنــا التقليدية هي التجاور و التقـــارب وان مسـن المســاوئ المناخية في مدننا الحديثة هي التباعد بين البيوت فـــإذا كان التباعد ذا مردود سيئ فما هي النسبة التي يمكــنـن

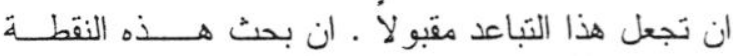
ودر اسة أثر هذا التباعد في المساكن لإعطلاء المصدسـم صورة و اضحة عن هذه الابعاد وما تسببه من مؤثرات سيساعدنا في الاقتر اب بمساكننا من الملائمة المناخيــــة وكذللك في التقلي.ــلـل مـن الاعتمــاد علــى الاجـــزة

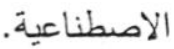

راجين ان تكون مساهمتتا المتو اضعة هـذه ذات

فائدة للمصممين و المصممين الحضريين في التقليل مـن

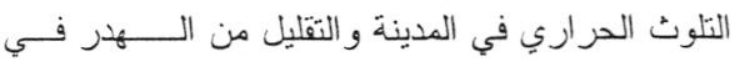

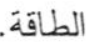

النسبيج الحضري

حدد المختصون في در اسـة النسيج الحضـــــري

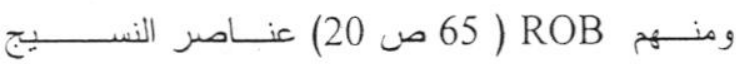
الحضر ي بالكتلة البنائية و الفر اغ الذي يحدها او يحبـط بها. فللفضاء الحضري عناصر مهمة رئيســـبة وهـيـي (الكتلة البنائية ، فضاء الشارع، المناطق الخضـــــاء)، ولدر اسة تأثير اتها على البيئة الداخلية للوحدة النــــكنية

بعد ان دخلت وسائط النقل الحديثة الـــى مدننــــا توسعت المدينة وكبرت مساحات البيوت عن ما كـانت عليه في المدينة التقليدية وبهذا أصبحت الكتل البنائيـــة تتوسط قطعة الارض او تشغل جزءأ منها تاركة بينــها وبين البيوت المجاورة فر اغات على شكل مدـــرات او على شكل حدائق جانبية او خلفية اما و اجهات القطــــع فقد أثر وجود السيارة على مسافة ارتداد الكتل البنائيـــة عن حدود قطعة الارض كمربأ للسيارت وبهذا اصبحت و اجهات الابنية مبتعدة عن بعضها مسافة تقارب عــن

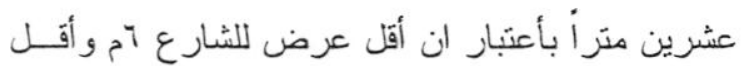
عرض رصنيف من كل طرف 1,0 متر إضافــة الـى ارتدادات الكتل البنائية عن حدود القطعة.

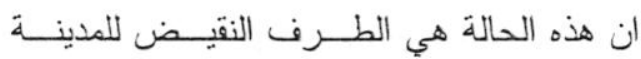
القديمة التي كانت البيوت متلاصقة فيــــها وذات أزقـــة ضيقة مظللة ساعد على تظليلها امتدادات الطوابق العليا

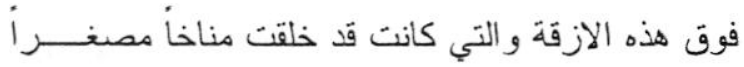
يختلف عن المناخ العام حيث نجده باردأ صيفاً و دافئن شتاءأ. ان هذه التغييز ات التي حدثت على المدينـة أدت الى تعرض الكتل البنائية الى تطرف المناخ فــأصبحت

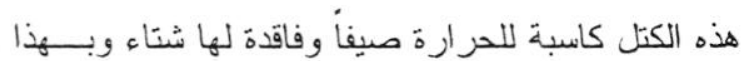

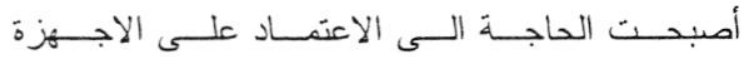
الاصطناعبية في التبزيد و التذفئة بشــــل كبــير حتـى

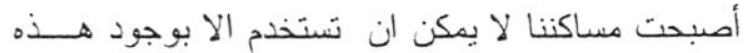
الاجهزة و على مدار السنة فز اد التلوث البيئسي و زادت

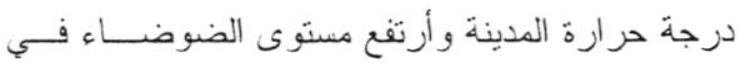
المدينة بشكل كبير . ان هذه التغير ات في المدينـــة أدت الى صعوبة العيش في المساكن دون الاعتمـــاد علــى الوسائل الميكانيكية و اذا ما انقطع التيار الكهريائي عـن

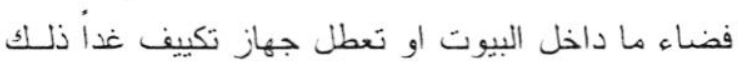


حرارة المنطقة نهارَاً أو لِيلاً بدرجات منفاوتــة. وسيتم اعتبار مادة بناء الجدران للكتلة البنائيـــة

$$
\text { قيد الدر اسة هي الطابوق. }
$$

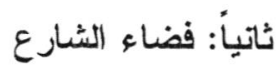

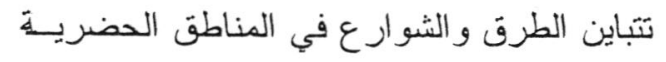
تبعاً لنوع الوظيفة التي تؤديها، فالشوار ع التـي تخــدم

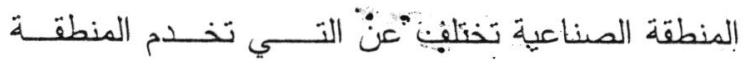
السكنية وهكذا . ومهن :أهم العو امل التي تحدد الكفـــاءة المناخية لفضاء الثار ع (r ص و ب): 1- نسبة ارتفاع المساكن الى عرض الطرق. r- توجيه شبكة الطرق r- مساحة التعرض للأشعة الشمسية ع- الاستقامة والانحناءات. - - مواد الانهاء المستخدمة في الثوارع. צ- الارتدادات (مسافة الترك النظامية). وفي هذا البحث سوف ينم اعتمــــاد أصغــر عـرض للشوارع السكنية تكفي لمرور ســـيارتين وهـي (Tدم) ومنطقة مرور سابلة بعرض (,0 1م) من كل جــــانب. وسترتد الكتلة البنائية عن حدود القطعة الامامية مسـلفة (Tدم) (كأقل طول لأيو اء سيارة واحدة). ثالثاً: المناطق الخضر اء

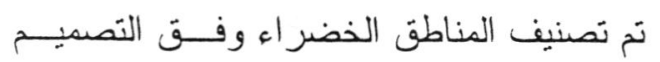
الاساس لمدينة بغداد (أمانة بغداد) الى عدة أنو اع وهي: ا-ترفيهية. ب- زر اعية عامة. ب- مفتوحة.

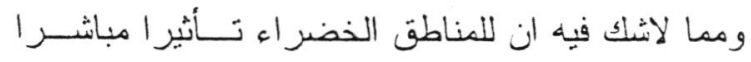
على عو امل مناخية عديدة و أهم هذه العو امل هــــي: درجات الحرارة - الرطوبة النسبية - سرعة الريـــاح - الاشعاع الشمسي بكل مركباته

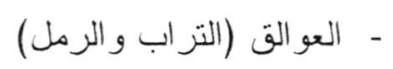

في هذا البحث سوف ينت التطرق الى أثــــر اســــذام

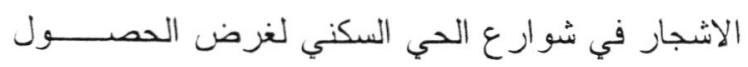
على الظلل و أثر ذلك في التقليل مــن كميــة الاشــعاع

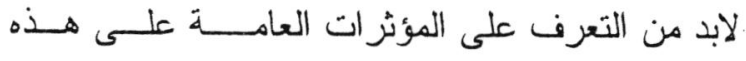
العناصر و على طرق تشكيلها وتنظيمها فـــي النســيِج

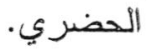

أولاً: الكتلة البنائبة تستحدث الكتلة البنائية ضمـــنـن موقَّع معيـن ظروف مناخية تختلف عن تلك الظروف قبل أنشـــاءها وتتبابن هذه التغير ات بشكل أساسي في:

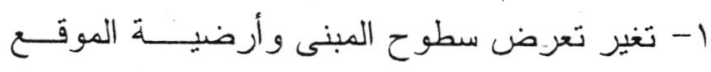
للأشعاع الشمسي. r- تغير حركة الهو اء ضنمن الموقع. 1- - أشكال الكتل البنائية: في دراسة أجريت في مركز بحوث البنــاء (د. الجو ادي و آخرون) وجد من مستح تم في مدينــة

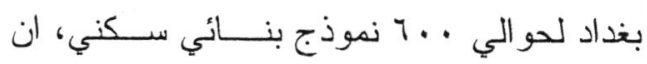
اشكال الكتل البنائية نقع في · ل أثنكال مجــردة كما في شكل (1) وسيتم في البحث اعتماد هـذا النموذج في المقارنات، وكانت النماذج البنائيـــة الممثلة بشكل (L) هي أكثر النماذج تكرار أ. r- الفواصل بين الكتل البنائية: في بعض حالات تجميع الكتل البنائيــة ضنــن المناطق السكنية يتم تــــرك مســافات فاصلـــة

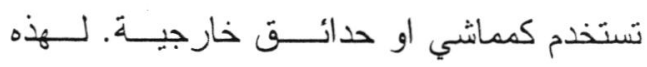

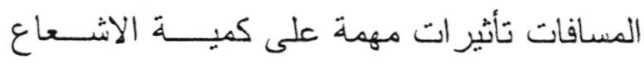
الشمسي الساقط على الجدران الخارجية للكتلـــة البنائية و المناخ الخاص بالمنطقة. كما ان منافة الارتداد الامامية كما حددتها المعايير و الأنظمـــ المحلية ساهمت في زيادة المسافات بين الكتــلـل البنائية المتقابلة. r- مواد أنهاء الكتل البنائية: تختلف فابلية المو اد البنائية المختلفة على عكس و امتصاص الاشعاع الشمسي بحسب خو اصــــا الفيزيائية ولهذه الخو اص تاثير علــــى درجـــة 
و لأغر اض تبسيط عملية البحث و الدر اسة ســـوف يتــم الاعتماد على الاشعاع الشمسي بكل مركباتـــه و وعلـى درجة حر ارة الهو اء الخارجية المعتمـــدة لــدى هيئـــة الأنو اء الجوية كمؤثرات علــى المكونــات الاساســية للنسيج الحضري، وسيتم اعتماد مفهوم درجة حـــرارة الهو اء الشمسية (Sol-air-temp) كمؤثر أجمالي لتلـك المظاهر وسوف لن يتطرق البحث حالياً الـــى تـأثير سرعة الرياح ولا الرطوبة النسبية وتحسب كل ساعة خلال ســــاعات ظــــور الاشـــاع الشمسي من المعادلة الآتية ( 3 ص 370):

$$
F_{\text {total }}=\frac{10000}{r_{0}} \times(t a-t b)+a \times I_{\text {day }} \times A
$$

F total

$$
\text { الثمسية (w) بالو اط. }
$$

r0 مقاومة السطح الخارجي لنفاذ الآثـــر الحــر اري ro .(deg.cm2/w)

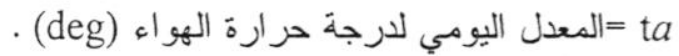
=tb درجة حرارة الفضاء الداخلي (deg). = دالة لقيم امتصاصية السطح الخارجي. Iday = أجمالي محصلة الاشعاع الشمسي لذلك السطح

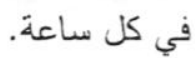
A المساحة السطحية للجــدر ان و السـقوف وتقــاس $\cdot\left(\mathrm{m}^{2}\right)$

في هذا البحث سوف يتم تحديد مســــاحة القطــع السكنية بـ (400 منز مربع) بأبعـــاد (16م 25Xم ) ويوضح (الثكل r ) أبعاد الكتل البنائية والقطع السـكنية

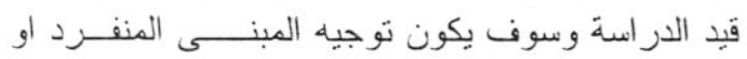

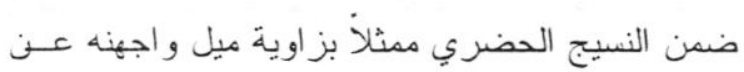
الشمال الحقيقي كما في (الثــــكل r) وســـيتم اعنمــاد التوجهات الثُان الرئيسية (الشمال، الثمال الثــــرقي،
المباشر الساقط على الكتل البنائية صيفأ وحساب أثـــر ذلك في كمية الطاقة الشمسية التـــي تســتقبلها الكتلـــة

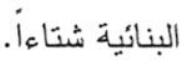

وبأعنبار ان المصمم الحضري يجب ان يسـأخذ بعيسن الاعتبار السلامة العامة لمستخدمي الشارع فأن لأشجار الشو ار ع مو اصفات عامة سنداول الثقيد بها وهي:

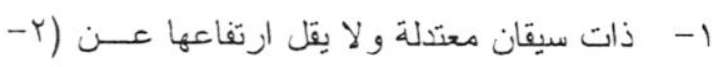

$$
\text { "م) حتى لا تعيق حركة السير. }
$$
r- خالية من الاشو الك.

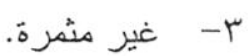

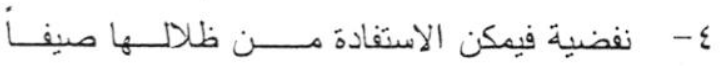
وسماحها لنفوذ الاشعة الشمسية شتاءأ. 0- سريعة النمو قابلة للقص و التشكيل. 7- متوفرة و رخيصة الثن وسهلة الاكثار . وبموجب هذه المو اصفات فقد اعتمد في البحــث شجرة الالبيزيا التي وجد انها أحدى الاثـــــار التــي تمنلك غالبية تلك الخصائص و التي يسهل زر اعتها في

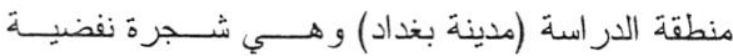
بيضوية الشكل أرتفاع ساقها حوالــــي (rم) وأرتفــاع مجمو عها الخضري حو الي (^م) و عرضــــــهـ حو الــي $(3) \cdot)$ وبعد ان تَم التعرف علــى مكونــات النســيِج الحضري ولمعرفة تأثير ها على كمية الطاقة المسـلطة على الكتل البنائية ضمن النسيج الحضري للتقليل مسنـ الطاقة المصروفة دأخل الوحدات السكنية لا بـــــــن التعرف ايضنأ على مظاهر الجهد الحراري الخــارجي المؤثرة على تلك المكونات. ومن أهم هـــذه المظــاهر 1- الاشعاع الثمسي بكل مركباته (مباشر ، منتشــر ومشتت)

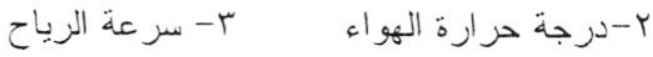

$$
\begin{aligned}
& \text { ع - الرطوبة النسبية }
\end{aligned}
$$


الحارة الجافة. و هذا المؤشر يؤكد بأن النسيج الحضري

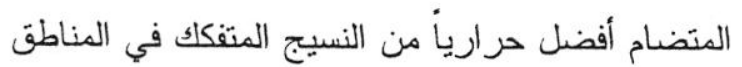
الحارة الجافة بسبب قلة المساحة السطحية المعرضــــة للأشعاع الشمسي المباثر الى المساحة السطحية الكليــة للمبنى الواحدُضمن النسيج الحضري.
الشرق، الجنوب الشرقي، الجنوب، الجنوب الغربـــي، الغرب و الشمال الغربي). مؤشر كفاعة النسبج الحضري مناخياً

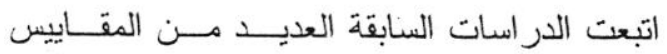
و المؤشرات التي استخدمت وما تز ال تستخدم لحد يومنا هذا في قياس كفاءة الابنية منفــردة او ضمسن نسـيـج حضري، ومن أهم هذه المؤشرات هو مؤشر الكفـــاءة المساحة السطحية الى الحجم الكلــــي للمبنـــى (S:V)

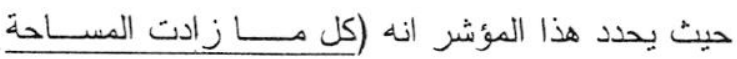
السطحية الكلية الي الحجم كلما قلت كفاءة المبنى). لكن هذا المؤشر او المقياس لا يعنبر دقيقاً فــــي المنــاطق الحارة الجافة حيث يكون فيها الاشعاع الشمسي المباشر ذو قيمة كبيرة فقد تتساوى المساحات السطحية وحجهوم الابنية ولكن كفاءتها المناخية تختلف من و احـــدة الــى الاخرى بسبب اختلاف المساحة السطحية المعرضــــة للأشعاع الشمسي المباشر الى المساحة السطحية الكليـة كما في (الشكل ؛). ومما ذكر نستنتج بـــأن المؤشسر (S:V) هــو مقياس غير صحيح فـــي المنـــاطق الحســارة الجافــة خصوصأ عندما تتجمع الكتــلـل البنائيسـة فــي نسـيجيج حضر ي. ومن الممكن وضع مؤشر جديد لقياس كفاءة

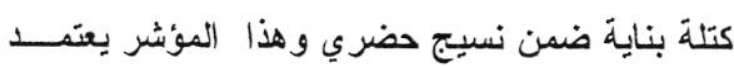
على: المساحة السطحية المعرضة للشعاع الثمسي المباشر المساحة السطحية الكلية للمبنى

فكلما زادت المساحة السطحية المعرضــــة الــى الاشعاع الشمسي المباشر الى المساحة السطحية الكليـة

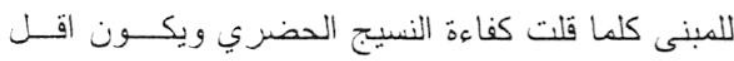

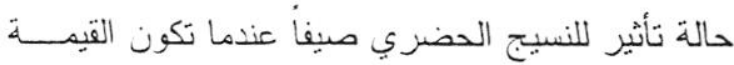
أعلاه مساوية الى (صفر)، ويقل التأثبر حتــى ينتسدم عندما تساوي (1)، و العكس بالعكس شنتاءأ في المناطق 


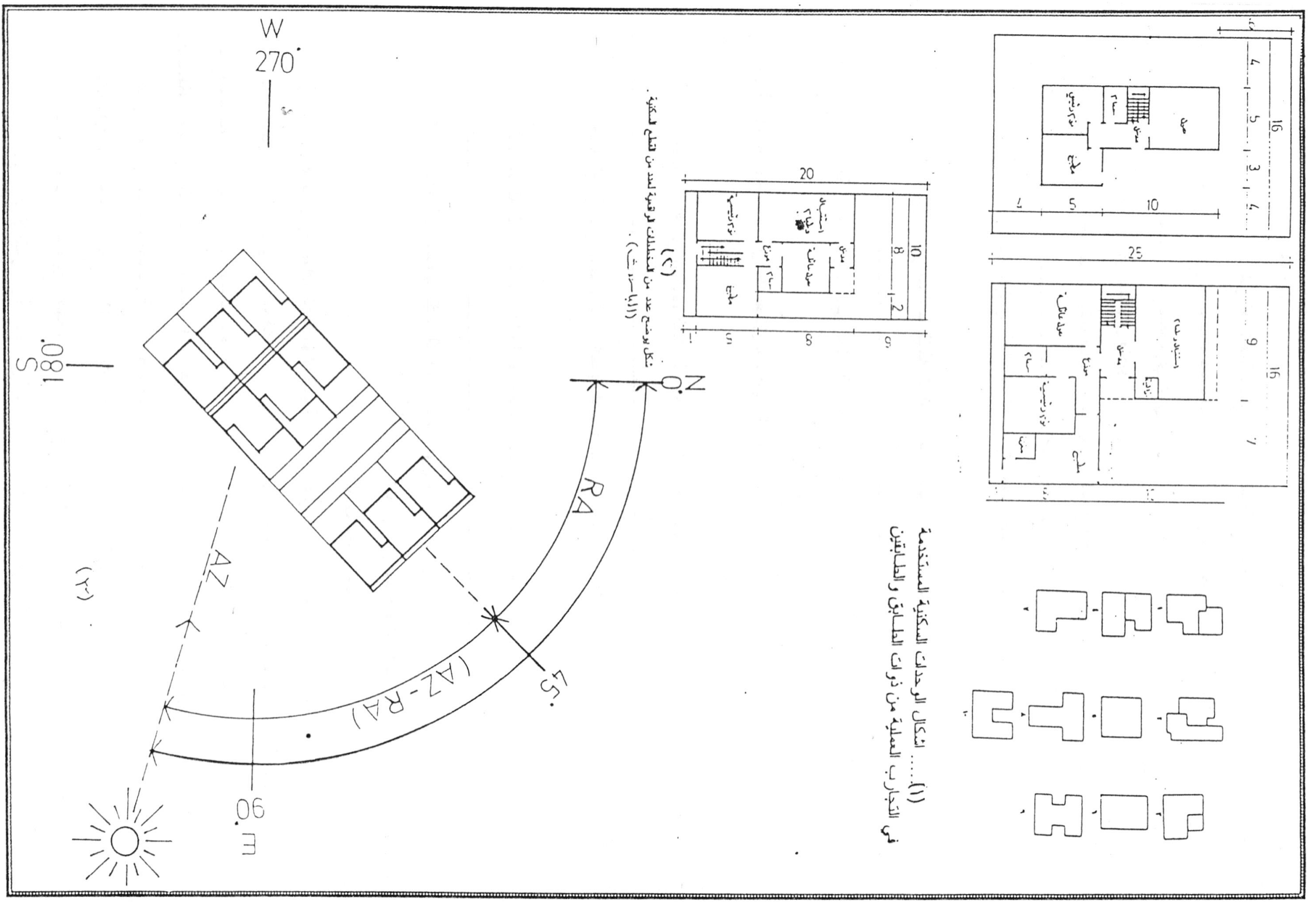


كمية الطاقة التي تستلمها نفس الكتالــة بمعـزل عـن

\section{طريقة قياس كفاعة النسبيج الحضري}

المجاور ات، وقد يكون تأثير النسيج الحضري ايجابيــنان

استخدمت طريقة قياس جديدة لقيــاس كفــاءة النســـيج او سلبياً في المناطق الحارة الجافة.

الحضري وهذه الطريقة تعتمد على حســــاب كميـات

الطاقة التي تستلمها الكتلة ضنمن النسيج الحضري الـى ان اعلى درجة من الكفاءة للنسيج الحضري تتحقق اذا كان: كمية الطاقة التي تستلمها الكتلة البنائية ضمن النسيج الحضري صيفاً =

كمية الطاقة التي تشتلمها الكتلة البنائية بدون وجود مجاور ات صيفاً

كمية الطاقة التي تسنلمها الكتلة البنائية ضمن النسيج الحضري شتاءأ $1=$

كمية الطاقة التي تستلمها الكتلة البنائية بدون وجود مجاورات شتاءi

وأن أسوأ كفاءة للنسيج الحضري عند تحقيق الثرطين التاليين:

كمية الطاقة التي تسنلمها الكتلة البنائية ضمن النسيج الحضري صيفاً $1=$

كمية الطاقة التي تستلمها الكتلة البنائية لوحدها بدون وجود مجاور ات صيفاً ،

كمية الطاقة التي تسنلمها الكتلة البنائية ضمن النسيج الحضري شتاءأ

| صنز = ..... r

كمية الطاقة التي تستلمها الكتلة البنائية لوحدها بدون وجود مجاورات شتاءأ

أخرى ومن أهم هذه الامكانيات هي الحرية في عمليـة

الرسم وطريقة حساب مساحات أسطح المبنى العموديـة

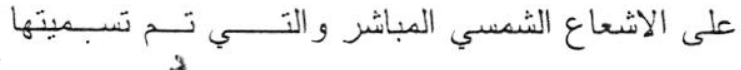

ولصعوبة حساب كمية الطاقة الكلبة الو اصلــــة

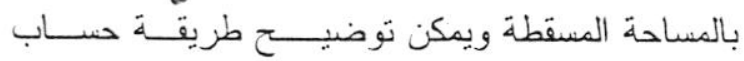
الى سطوح المبنى ساعيا وشهريا وشتويا فقد تم اعـداد المساحة المسقطة كما في (الثكل (0-أ)) حيث تَنــــل

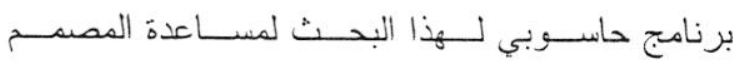
المساحة المسقطة ما تز اه الثمس من سطوح المبنى في و المخطط الحضري و الذي يمكن بو اسطته قياس كفــاءة

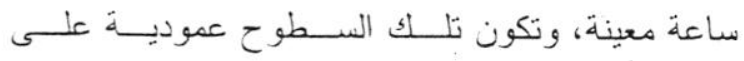
نسيج حضري معين، حيث تم تصميم البرنـــامج بلغـــة الاشعاع المباشر ، وهذه المساحة تختلف عن المســـاحة و ونتم ربطه ببرنــلمج (Auto-Cad13) وبرِ (Auto-lisp)

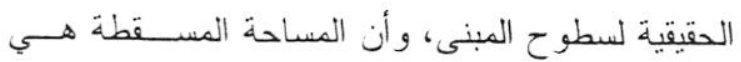
التي تدخل في عملية الحسابات.

وقد تمت عملية تصميم البرنامج بهذه اللغة لما تحتويـها هذه اللغة من امكانيات قد لا تكون موجودة فـــي لغـــة 
الحمل الحراري الخارجي على جدرانـــها بنســبة

$$
\% \varepsilon \cdot-\% \varepsilon r
$$

ץ- أما الاتجاهات الغربية و الشرقية و الجنوب الغربـي

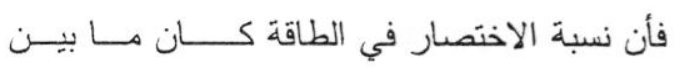

$$
\% r \wedge-\% \text { r }
$$

r- اما الاختصار في الطلةقة في الاتجــــــاه الجنوبــي

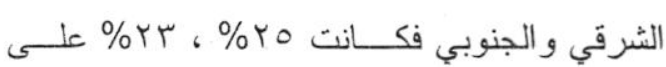

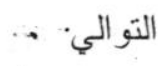

ثالثأ: حينما تكون المَّاكن مرتدة عن حافـــة القطعـة

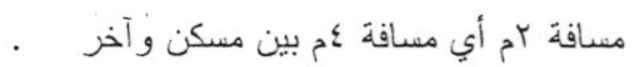
1- اظهرت النتائج ان المساكن المتجهة بأتجاه الشمال

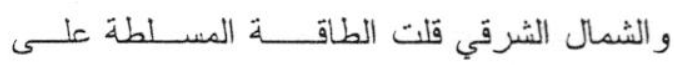

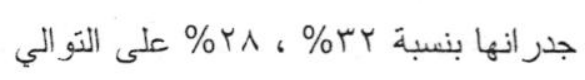

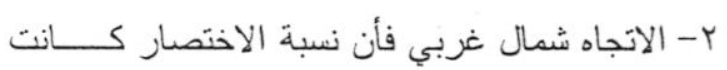

$$
\% \text { ro }
$$

ب- اما الاتجاهات جنوب، شرق وغرب فـــان نسـبة

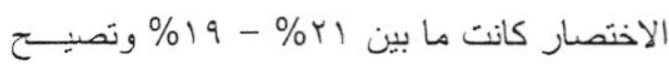

$$
\text { النسبة VI V في الاتجاه الجنوبي الشرقي }
$$

ر ابعاً: حينما يكون المسكن مرند مسافة سام عن حافـــة

$$
\text { القطعة أي آم بين مسكن و آخر }
$$

1- نسبة الاختصار في الطاقة الواصلة الى المبنى في

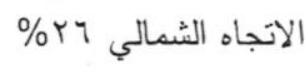

r- اما في الاتجاهات شمال شرقي، شـــمال غربــي،

جنوب، جنوب غربي فكانت نسبة الاختصار فـي

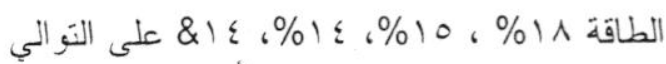

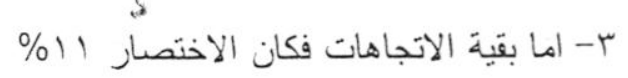

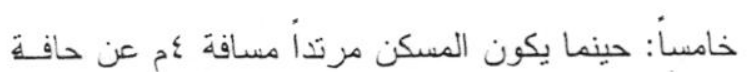

$$
\text { القطعة أي ^م بين مسكن و آخر }
$$

1- نسبة الاختصـار في الطاقة في اتجـــــاه الثــمال،

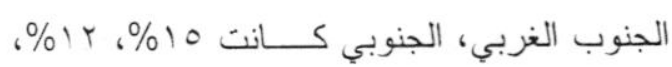

$$
\text { 11\% على التو الي }
$$

r اما بقية الاتجاهات فكانت بنسبة هی
ولحساب المساحة المسقطة لكتلة فـــي النســبِج

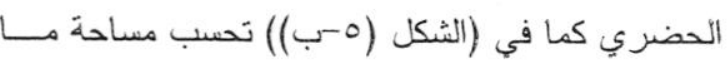

تز اه الشمس من الكتلة البنائية وجميع المجاورات التي

تسقط ظلاً في تلك الساعة كمرحلة اولى ومن ثم ينــم

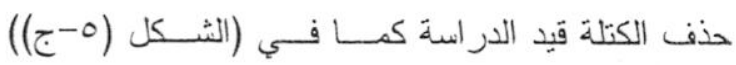
وتحسب المساحة المســــــة للكتــل المظللــــة للكتــل المدروسة. و الناتج من الفرق بين المساحة في الحالــــة الاولى و المنساحة في الحالـــة الثنانيــة الـــى المســاحة المسقطة للكنلة البنائية.

\section{نتئتج القِيَاس}

أظهرتت نتائج القياس بو اسطة برنامج تقييم أثر النســيِج الحضري مجموعة من الجداول التي أظهرت كميــات

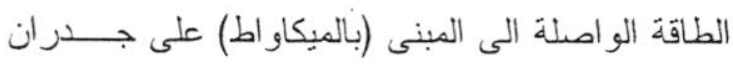

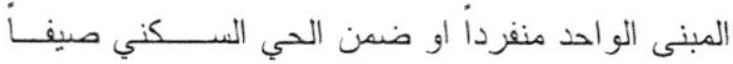

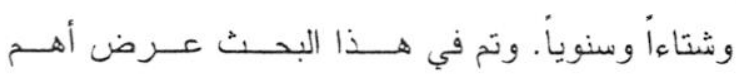
الاستنتاجات و التي ركزت على التأثبر السنوي للنســيج

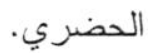
أولاً : حينما تكون المساكن متلاصقة من ثلاث جهات 1- أظهرت النتائج ان المساكن المواجهــــة للشــمال و الشمال الشرقي و الشمال الغربي قد قل الحمــــل

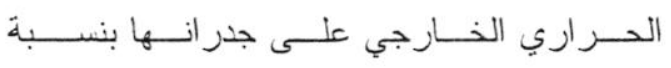
. $44 \%, 46 \%, 50 \%$

r- اما بقية الاتجاهات فكانت نسبة الاختصار ما بين

$$
30 \%-35 \%
$$

ثانياً : حينما تكون المنساكن مرتدة عن حافــة القطعـة

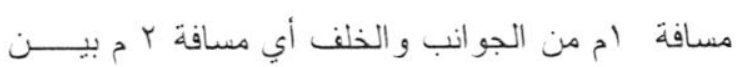
مسكن و آخر. 1- أظهرت النتــائج ان المســـاكن المتجهـــة بأتجـــاه الشمال، و الشمال الثرقي و الشمال الغربي قد قــلـ 
r. النعيمي، سعد فوزي، " أثــــر مكونــات الفضــــاء

الحضري على التقليل من الهدر بأستخدام الطاقــــة

داخل الوحدات السكنية" ، أطروحة ماجستير مقدمة

الى قسم الهندسة المعمارية، الجامعة التكنولوجيـة،

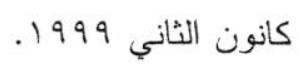

4. Evans, M., "Housing, climate \& comfort", The Architectural press, 1980.

5. Krier, Rob, "Urban space" Academy editions, London, 1979.
سادسأ: ان افضل اختصسار في الطاقة المســلطة علــى المبنى في كل الحالات في الالتصاق من ثلاث جـــات

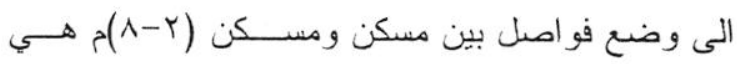
حينما تكون الواجهة مقابلة للشمال يليها الشمال الشرقي و الثمال الغربي اما بقية الاتجاهات فيكاد التمايز بينــها في الاختصار الطلقة المسلطة منقاربأ ولا يزيسـد عـنـن .$\% 9$ سابعاً: لقد وجد بأن تأثير اشجار الشوارع المزروعـــة

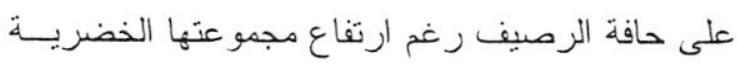

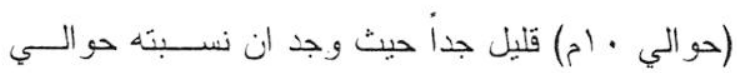
r\% عند تلاصق الجدران الجانبية في البيوت في الحي السكني أمـا في البيوت المرتدة ام عن حافـــة القطعـة وحتى عم أي كام الى ^م بين منكن و آخر فأنه نســـبة الاختصار في الطاقة الساقطة على الجــدران حوالــي 1\% مما يدل على ان عملية نشجيز الشــــوارع علـى مسافة Vم في المبنى غير ذات فائدة تذكر في عمليــــة

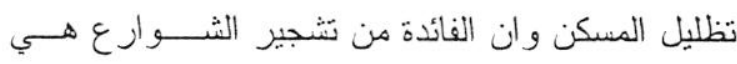
لتظليل الارصفة و الشارع وتقليل الحمل الحراري الذي تستقبله مادة الرصيف و الثار ع مما يقلل مــن درجــة حرارة هو اء الشارع ثامناً: يقل تأثير النسيج الحضري في المواء ازنة المناخيـة كلما ز ادت مسافات الترك الجانبية و الخلفية . تاسعاً: افضل نسيج حضر يـ يكون حينما تكــون كتلــه

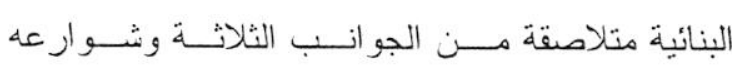

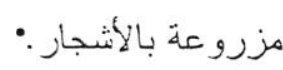
المصادر 1. التصميم الاساسي لمدينة بغذاد، التقرير النــــهائي،

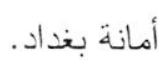
Y. د. الجو ادي، مقـــداد و آخــرون، "تـأثيز الثــكل الهندسي للفضاء الحضري على تضليله" ، بحــوث المؤتمر العلمي الخامس لمجلس البحث العلىــــي، بغداد، V-11 التربن الثاني 1919. 


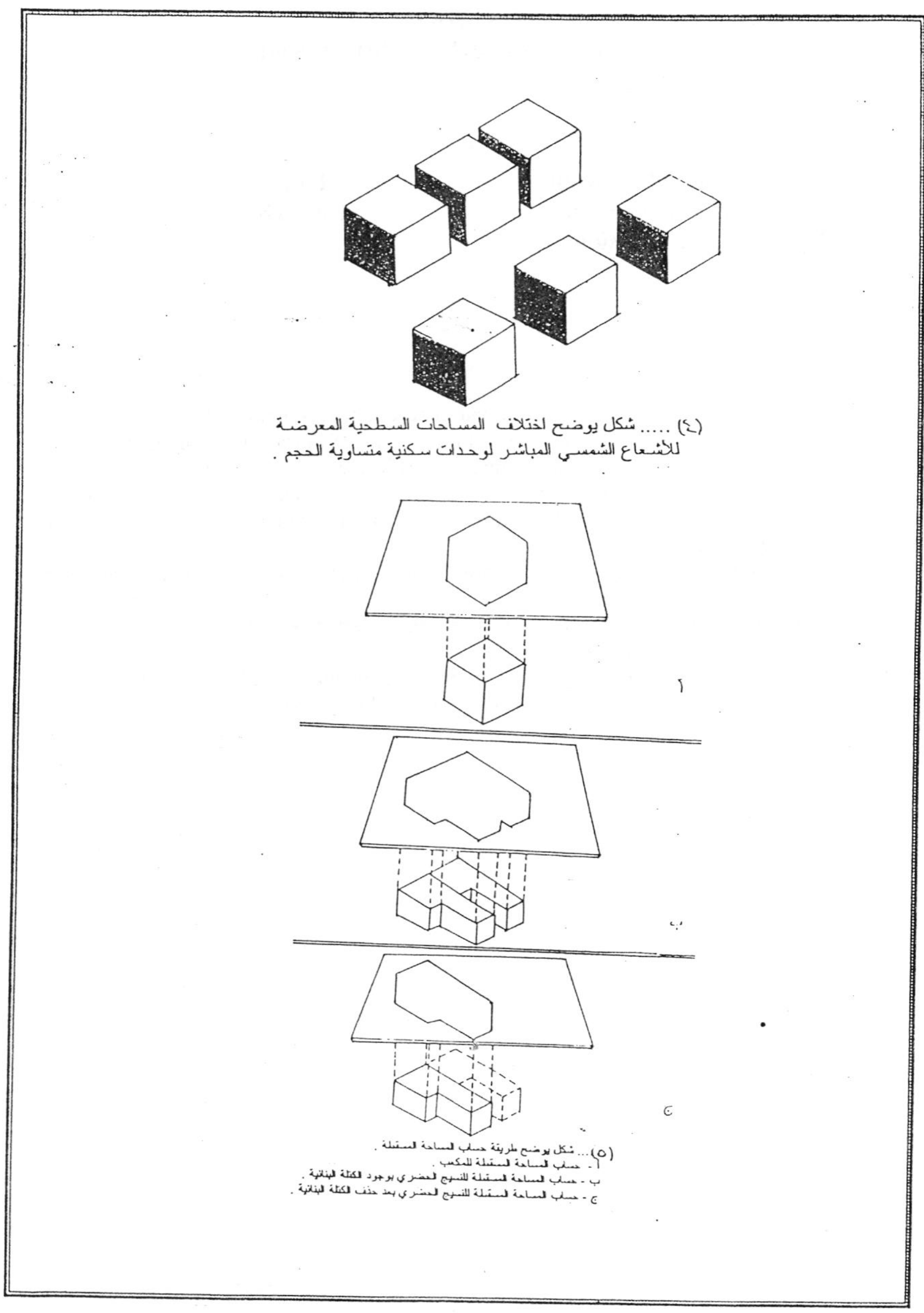


Effect of sides and back distances between buildings on the quantity of energy impact on building mass in urban fabric in Iraqi housing projects

\author{
Dr. Miqdad AL-Jawadi \\ Dept. of Architecture \\ University of Technology
}

\author{
Saad Fawzi AL-Naeemi \\ Msc. Urban design
}

\begin{abstract}
:
This paper deals with the effect of inter-house distances in new cities on the thermal comfort inside houses, as well as the effect of increasing such distances on energy waste and the increase of dependency on air-conditioning and artificial aids.

In this paper comparison has been done between the quantity of energy impact on separated houses and energy quantity impact of the same mass in urban fabric (for housing projects having similar houses).

The study has been carried out for case of attaching from three sides and for detached houses with inter-house distances between 2-8 meters.

Results have been give for two cases, the first when streets are without trees and the second- when streets are planted with trees.

The results were obtained by using computer program designed especially for this research. And is designed to be connected to Auto CAD (13) program.
\end{abstract}

